\title{
Perfis proteicos e desempenho fisiológico de sementes de café submetidas a diferentes métodos de processamento e secagem
}

\author{
José Henrique da Silva Taveira(1), Sttela Dellyzete Veiga Franco da Rosa(2), Flávio Meira Borém(1), \\ Gerson Silva Giomo ${ }^{(3)}$ e Reni Saath ${ }^{(3)}$
}

\begin{abstract}
(1) Universidade Federal de Lavras, Departamento de Engenharia, Caixa Postal 3037, CEP $37200-000$ Lavras, MG. E-mail: henriquetaveira@yahoo.com.br, flavioborem@deg.ufla.br (2)Embrapa Café, Avenida W3 Norte (Final), Parque Estação Biológica, CEP 70770-901 Brasília, DF. E-mail: sttela.rosa@embrapa.br ${ }^{(3)}$ Instituto Agronômico, Avenida Barão de Itapura, no 1.481, Caixa Postal 28, CEP 13020-970 Campinas, SP. E-mail: gsgiomo@yahoo.com.br, reniagricola@yahoo.com.br
\end{abstract}

Resumo - O objetivo deste trabalho foi avaliar os perfis proteicos e o desempenho fisiológico de sementes de café submetidas a diferentes métodos de processamento e secagem. Foram avaliados os processamentos por via seca e úmida, e as secagens natural, em terreiro, e artificial a $60^{\circ} \mathrm{C}$, ou a $60^{\circ} \mathrm{C}$ até $30 \%$ de umidade e $40^{\circ} \mathrm{C}$ até teor final de $11 \%$ (base úmida). Após serem processadas e secadas, as sementes foram avaliadas quanto ao desempenho fisiológico e submetidas a análises bioquímicas, por meio da eletroforese de proteínas resistentes ao calor LEA ("late embryogenesis abundant") e das enzimas superóxido dismutase, catalase, peroxidase, esterase, polifenoloxidase, isocitrato desidrogenase, álcool desidrogenase e malato desidrogenase. O perfil proteico de sementes de café é afetado pelo método de processamento e de secagem. Os cafés processados por via úmida apresentam maior tolerância à secagem - revelada pela maior atividade de enzimas antioxidativas e pelo melhor desempenho fisiológico - do que os processados por via seca. A atividade de proteínas resistentes ao calor e de enzimas antioxidantes é variável promissora para diferenciar a qualidade dos cafés submetidos a diferentes manejos pós-colheita.

Termos para indexação: Coffea arabica, enzimas antioxidativas, manejo pós-colheita, proteínas LEA, proteínas resistentes ao calor.

\section{Protein profiles and physiological performance of coffee seeds subjected to different processing and drying methods}

\begin{abstract}
The objective of this work was to evaluate the protein profiles and physiological performance of coffee seeds subjected to different drying and processing methods. We evaluated processing by dry and wet routes, the drying methods: natural, on the patio, and artificial at $60^{\circ} \mathrm{C}$, or at $60^{\circ} \mathrm{C}$ until $30 \%$ of moisture content and $40^{\circ} \mathrm{C}$ until $11 \%$ (wet basis). After processing and drying, the seeds were evaluated as to their physiological performance and subjected to biochemical analyses with electrophoresis of heat-resistant LEA (late embryogenesis abundant) proteins and of the enzymes superoxide dismutase, catalase, peroxidase, esterase, polyphenol oxidase, isocitrate dehydrogenase, alcohol dehydrogenase, and malate dehydrogenase. The protein profile of coffee seeds is affected by the processing and drying methods. The coffee processed by wet route has higher tolerance to drying - shown by the higher activity of antioxidative enzymes and better physiological performance - than that processed by dry route. The activity of heat-resistant proteins and antioxidant enzymes is a promising variable for the differentiation of the quality of coffee subjected to different postharvest management.
\end{abstract}

Index terms: Coffea arabica, antioxidative enzymes, postharvest management, LEA proteins, heat-resistant proteins.

\section{Introdução}

Durante o processamento e a secagem do café, os grãos estão sujeitos a alterações físicas, bioquímicas e fisiológicas que podem influenciar aroma e sabor (Bytof et al., 2007; Borém, 2008). Entre essas alterações, Borém et al. (2008) e Marques et al. (2008) destacam os efeitos dos manejos pós-colheita sobre a integridade dos sistemas de membranas.

Alterações na qualidade do café, na pós-colheita, constituem um fenômeno ainda pouco conhecido e alvo de avançados estudos. Os eventos que ocorrem nessa fase podem interferir negativamente na qualidade dos grãos e devem ser rapidamente detectados para 
prevenção. Portanto, estudos de sistemas enzimáticos podem contribuir para o entendimento dos eventos deteriorativos que culminam em queda na qualidade de bebida dos grãos e no desempenho fisiológico das sementes.

Bytof et al. (2007) constataram que cafés processados por via úmida, ou despolpados, apresentam maior atividade de enzimas relacionadas ao final da embriogênese, associadas ao metabolismo da germinação, tais como a isocitrato liase e a $\beta$-tubulina. Livramento (2008), ao avaliar cafés naturais (processamento via seca) e despolpados, secados em terreiro ou com ar aquecido a $60^{\circ} \mathrm{C}$, observou que, além do processamento, a temperatura do ar de secagem também tem forte influência na constituição bioquímica do produto final. Além disso, durante o processamento e a secagem de sementes e grãos, podem ocorrer alterações na composição relativa de fosfolipídios de membranas (Dussert et al., 2006), na síntese de proteínas resistentes ao calor e na capacidade das sementes em prevenir, tolerar ou reparar danos por radicais livres (Berjak, 2006).

As proteínas resistentes ao calor, as quais se acumulam em resposta ao ácido abscísico, na fase final de maturação - por isso, denominadas, também, de proteínas "late embryogenesis abundant" (LEA) -, têm função protetora na prevenção de danos causados pela redução nos teores de água nas sementes (Berjak, 2006; Vidigal et al., 2009). Essas proteínas apresentam função protetora nas sementes e têm grande importância na prevenção de danos por secagem (Guimarães et al., 2002; Faria et al., 2003; Vidigal et al., 2009). Nesse contexto, cabe ressaltar que essa proteção de membranas celulares pode resultar na retenção de componentes formadores do sabor e do aroma nas células.

Outro tipo de proteção importante que ocorre nas sementes é a exercida por sistemas antioxidantes contra a ação de radicais livres. Se a ação de radicais livres não for controlada, eles podem alterar a funcionalidade das membranas e promover a peroxidação de lipídios, a inativação de enzimas e a degradação de ácidos nucléicos (Greggains et al., 2000). Portanto, baixa atividade de enzimas removedoras de peróxidos contribui para a deterioração dos grãos. Segundo Berjak (2006), a redução na atividade de enzimas removedoras de radicais livres aumenta a sensibilidade das sementes a estresses oxidativos. As enzimas superóxido dismutase, catalase e peroxidase compõem o principal sistema enzimático contra radicais livres (Berjak, 2006).

A oxidação de polifenóis, pela enzima polifenoloxidase, é outro evento bioquímico que pode prejudicar a qualidade de bebida do café. De acordo com Goulart (2003), este mecanismo é considerado como uns dos principais indutores da depreciação da qualidade da bebida do café. A redução na atividade dessa enzima também está relacionada à integridade do sistema de membranas.

Além das enzimas já mencionadas, outras também estão ligadas ao processo de deterioração das sementes e dos grãos, como a esterase, a isocitrato desidrogenase e a malato desidrogenase (Coutinho et al., 2007).

O objetivo deste trabalho foi avaliar os perfis proteicos e o desempenho fisiológico de sementes de café submetidas a diferentes métodos de processamento e secagem.

\section{Material e Métodos}

Foram avaliados dois métodos de processamento e três formas de secagem de café (Coffea arabica L. 'Catuaí Vermelho IAC 99'), tendo-se utilizado o delineamento inteiramente casualizado, em arranjo fatorial $(2 \times 3)$, com três repetições.

O café, colhido na safra 2008/2009, foi selecionado manualmente, tendo-se buscado a uniformidade dos frutos no estádio cereja de maturação. Os frutos foram processados por via seca (café natural) e úmida (café despolpado), de acordo com a metodologia proposta por Borém (2008). Após o processamento, os grãos de café foram secados em terreiro ou com ar aquecido a $60^{\circ} \mathrm{C}$ ou temperatura alternada de 60 a $40^{\circ} \mathrm{C}$. A parcela que recebeu o tratamento com ar aquecido a $60^{\circ} \mathrm{C}$ permaneceu no secador até que o teor de água atingisse $11 \pm 0,5 \%$ (base úmida, bu). Já o tratamento com ar aquecido a 60 e $40^{\circ} \mathrm{C}$, foi secado com temperatura de $60^{\circ} \mathrm{C}$ até atingir teor de água de $30 \%(\mathrm{bu})$ e finalizado com $40^{\circ} \mathrm{C}$ até o teor final de água de $11 \%$ (bu).

A secagem com ar aquecido foi feita com secador de camada fixa, de $0,15 \mathrm{~m}$, acoplado a condicionador de ar de alta precisão, conforme proposto por Fortes et al. (2006), com controle de temperatura (T) e umidade relativa (UR) do ar de secagem. Para garantir uniformidade nas condições de secagem, independentemente das variações ambientais, utilizouse o valor constante de $19 \%$ para a umidade relativa, 
quando o ar ambiente foi aquecido a $40^{\circ} \mathrm{C}$, e de $7 \%$, quando o ar foi aquecido a $60^{\circ} \mathrm{C}$. Esses valores foram obtidos a partir das características termodinâmicas do ar aquecido e das condições ambientais médias da região Sul de Minas Gerais (Borém, 2008).

Os grãos foram macerados em nitrogênio líquido, na presença de PVP (polivinilpirrolidona), e as amostras foram armazenadas em "deep-freezer" a $-80^{\circ} \mathrm{C}$, até a realização das análises.

Utilizou-se a metodologia proposta por Alfenas (2006) para extração, corrida eletroforética e revelação das proteínas resistentes ao calor e das isoenzimas superóxido dismutase (SOD), catalase (CAT), esterase (EST), polifenoloxidase (PPO), peroxidase (PO), álcool desidrogenase $(\mathrm{ADH})$, malato desidrogenase $(\mathrm{MDH})$ e isocitrato desidrogenase (IDH).

Os grãos foram submetidos à avaliação da qualidade fisiológica, por meio de testes de germinação, de acordo com as Regras para análises de sementes (2009). Nesses testes, foram determinadas as percentagens de protrusão radicular após 15 dias da semeadura, de plântulas normais após 30 dias e de plântulas com folhas cotiledonares após 45 dias.

\section{Resultados e Discussão}

Independentemente do método de processamento e secagem utilizado, a atividade de proteínas resistentes ao calor ocorreu em todos os tratamentos (Figura 1). Essas proteínas são sintetizadas e acumuladas nos estádios mais tardios do desenvolvimento dos grãos, antes ou durante a secagem. Embora não completamente esclarecida, sua função está associada à tolerância à dessecação e à proteção dos sistemas de membranas (Berjak, 2006). Pôde-se observar que grãos despolpados tiveram atividade mais intensa destas proteínas, comparada à de grãos processados por via seca (processamento natural). Guimarães et al. (2002) sugeriram que modificações ocorridas no perfil de proteínas resistentes ao calor reduzem a tolerância à dessecação das sementes de café. Além de menor atividade de proteínas resistentes ao calor, as sementes processadas por via seca também apresentaram menor tolerância à secagem, o que foi revelado por seu pior desempenho fisiológico (Figura 2).

A redução na atividade das enzimas removedoras de radicais livres (SOD, PO e CAT) - detectada pela análise de seus padrões eletroforéticos (Figura 1) - está relacionada à perda de viabilidade das sementes (Berjak,
2006). Esses sistemas enzimáticos estão envolvidos na resposta antioxidativa para neutralizar o oxigênio singleto e outros radicais livres formados sob condições de estresse (Dussert et al., 2006), como as que ocorrem durante a secagem. Segundo Berjak (2006), os danos em membranas, pela dessecação, podem ser causados por oxidação, que promove esterificação fosfolipídica ou peroxidação de lipídios.

Observou-se maior atividade da enzima CAT em grãos de café natural, processados por via seca, e nos grãos secados a 60 e a $60 / 40^{\circ} \mathrm{C}$ (Figura $1 \mathrm{D}$ ), os quais também apresentaram piores desempenhos fisiológicos (Figura 2). Essa enzima está envolvida na remoção de peróxidos de hidrogênio $\left(\mathrm{H}_{2} \mathrm{O}_{2}\right)$ das células, e sua maior atividade pode estar associada à diminuição de mecanismos de prevenção de danos oxidativos (Bailly et al., 1996). Esses resultados não concordam com os de Brandão Júnior et al. (2002), que verificaram decréscimo da atividade da catalase em sementes de café com menor desempenho fisiológico resultante de dessecação. Provavelmente, a maior atividade da CAT nos grãos de cafés secados nos frutos (processamento natural) deveu-se à alta produção de peróxido de hidrogênio $\mathrm{H}_{2} \mathrm{O}_{2}$, resultante da atuação da enzima SOD (Figura 1 B) na remoção dos radicais livres.
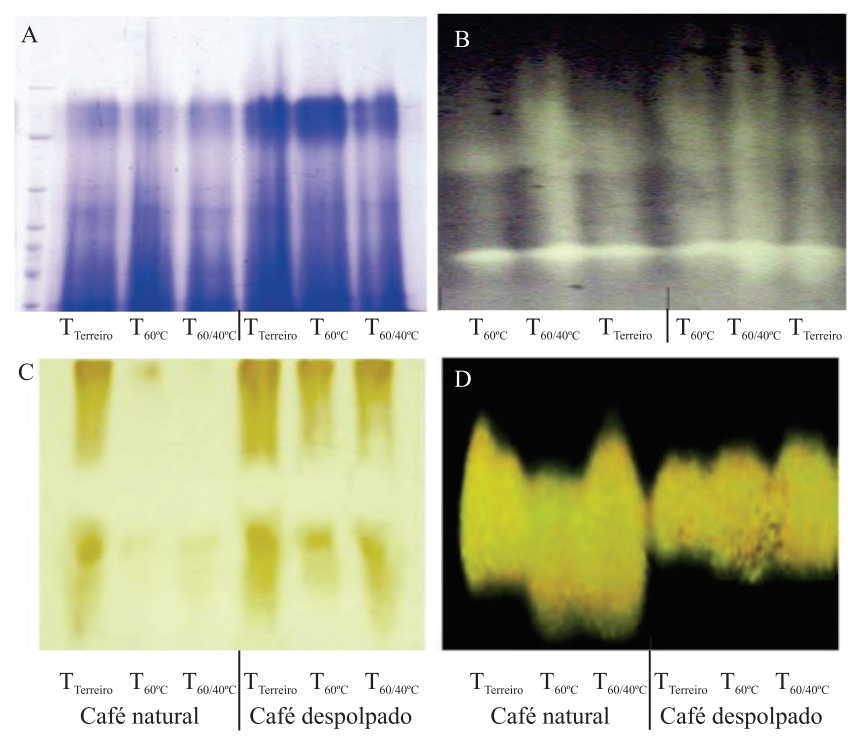

Figura 1. Padrão eletroforético de proteínas resistentes ao calor (A) e das isoenzimas superóxido dismutase (B), peroxidase (C) e catalase (D), em sementes de café submetidas aos processamentos via seca (café natural) e via úmida (café despolpado), secadas em terreiro $\left(\mathrm{T}_{\text {Terreiro }}\right)$ e em secador a $60\left(\mathrm{~T}_{60^{\circ} \mathrm{C}}\right)$ e a $60 / 40^{\circ} \mathrm{C}\left(\mathrm{T}_{60 / 40^{\circ} \mathrm{C}}\right)$. 
Nkang et al. (2000) constataram decréscimo nas atividades de CAT e SOD, associado a aumento nos níveis de hidroperóxidos, durante o processo de secagem de sementes de Telfairia occidentalis. Li \& Sun (1999) observaram aumentos na peroxidação de lipídios em eixos embrionários de Theobroma cacao, durante dessecação, relacionados a decréscimo nos sistemas enzimáticos de proteção. Segundo estes autores, esses resultados indicam aumento no teor de radicais livres oxidativos que, apesar de não quantificado, foi confirmado pelo aumento da lixiviação de eletrólitos e pela perda de viabilidade das sementes intolerantes à dessecação. Similarmente, Tawfik \& Huyghebaert (1999) relataram que a exposição dos ácidos graxos à oxidação causada pela desestruturação da membrana é um dos principais fatores depreciativos da qualidade de alimentos, por causar rancificação. Pôde-se observar que o café processado via seca (natural) e secado artificialmente apresentou menor atividade da enzima PO (Figura 1 C). Já o café despolpado, apresentou maior atividade da enzima PO e melhor qualidade fisiológica (Figura 2). Assim como SOD e CAT, a PO está associada à remoção de produtos indesejáveis da peroxidação de lipídios, em sementes e grãos.

O café processado via seca (natural) e secado artificialmente apresentou menor atividade da enzima PO (Figura 1 C). De acordo com Borém (2008), o café proveniente do processamento via seca (natural) requer exposição mais prolongada ao ar de secagem do que o despolpado, para ser seco. Dessa forma, o perfil eletroforético da PO pode ser um indicador fisiológico da desnaturação das sementes de café, causada pela exposição prolongada a elevadas temperaturas. Brandão Júnior et al. (2002) também verificaram redução na atividade dessa enzima em sementes de café danificadas pela secagem, as quais são mais sensíveis à dessecação. Portanto, os cafés secados nos frutos (processamento natural) deverão ter menor tolerância à dessecação em comparação aos despolpados. Essa suposição é corroborada pelo melhor desempenho fisiológico observado nos cafés despolpados (Figura 2).

A atividade da enzima EST foi maior nos grãos de cafés despolpados, processados por via úmida, quando comparada à ocorrida no café natural (Figura $3 \mathrm{~A}$ ). Além disso, aparentemente, os grãos despolpados, secados em terreiro, apresentaram maior atividade dessa enzima do que os submetidos à secagem de
$60 / 40^{\circ} \mathrm{C}$, mas atividade semelhante aos secados a $60^{\circ} \mathrm{C}$. No entanto, nos grãos de café natural secados em terreiro, a esterase apresentou maior atividade do que nos despolpados, também secados em terreiro.
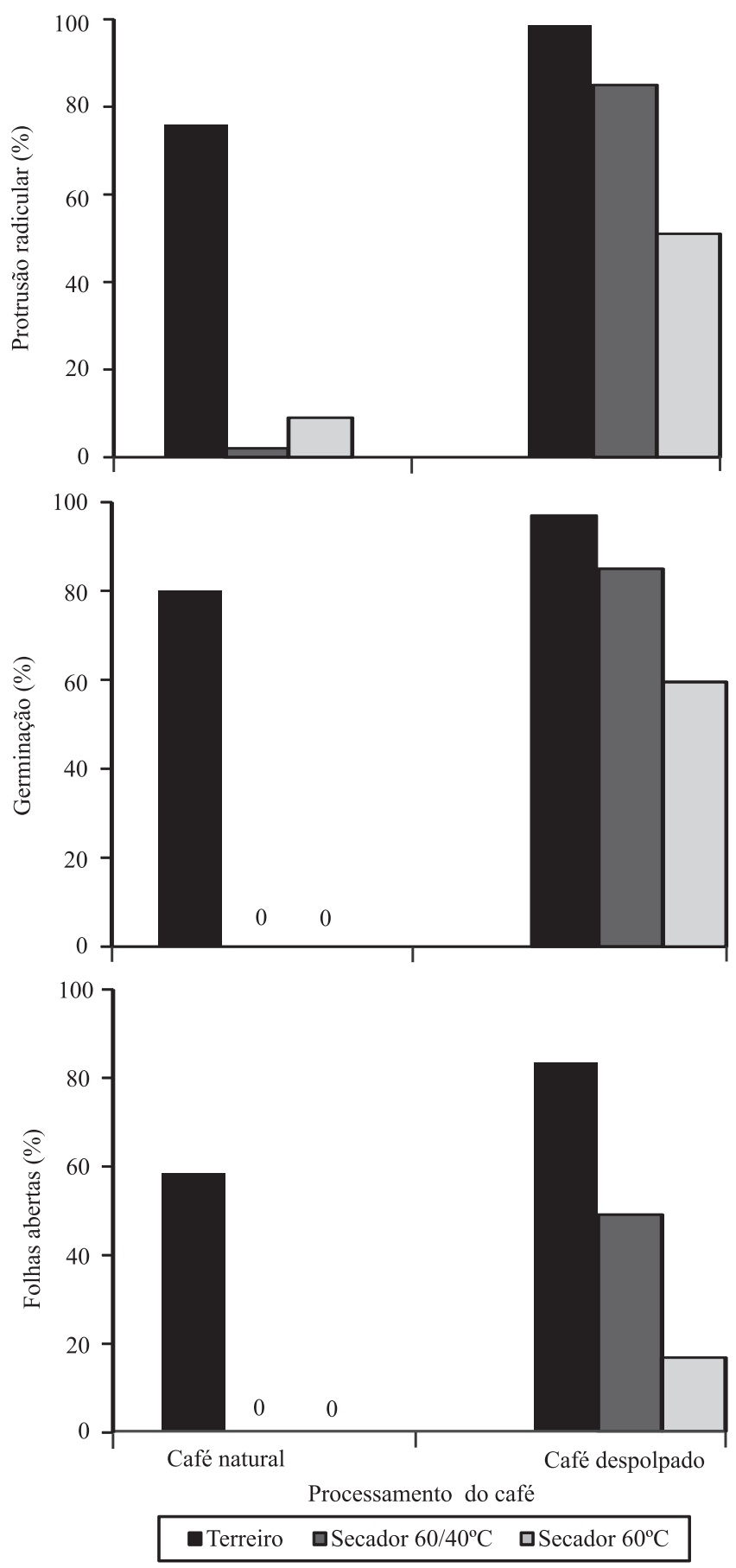

Figura 2. Desempenho fisiológico das sementes de café processadas via seca (café natural) e via úmida (café despolpado), secadas em terreiro e em secador a 60 e a $60 / 40^{\circ} \mathrm{C}$. 
A enzima esterase participa das reações de hidrólise de ésteres e pode, também, atuar sobre os fosfolipídios de membrana (Taiz \& Zeiger, 2004). Brandão Júnior et al. (2002) observaram aumento na atividade e no número de bandas dessa enzima em sementes envelhecidas ou danificadas.

A intensidade das corridas da enzima PPO foi bem diferente entre os cafés naturais e os despolpados (Figura 3B). Os primeiros apresentaram menor atividade da enzima do que os últimos. Essa enzima encontrase ligada às membranas celulares e é ativada quando ocorre ruptura nestas. A PPO atua sobre os compostos fenólicos, os quais conferem ao café sabor adstringente indesejável, quando em quantidades elevadas (Goulart, 2003; Santos et al., 2009). Entretanto, esses compostos têm importante função antioxidante e de proteção de aldeídos, como os ácidos clorogênicos e o caféico. Quando ocorrem danos nas membranas, essas enzimas são liberadas e ativadas, e podem reagir com substratos fenólicos intra e extracelulares, e transformá-los em quinonas (Amorin, 1978).

Esses resultados confirmam os de Santos et al. (2009), que verificaram alta atividade da enzima PPO em cafés despolpados. Pimenta \& Vilela (2003) relataram que a baixa atividade da PPO está relacionada a cafés com qualidade inferior, provenientes de frutos secos ainda
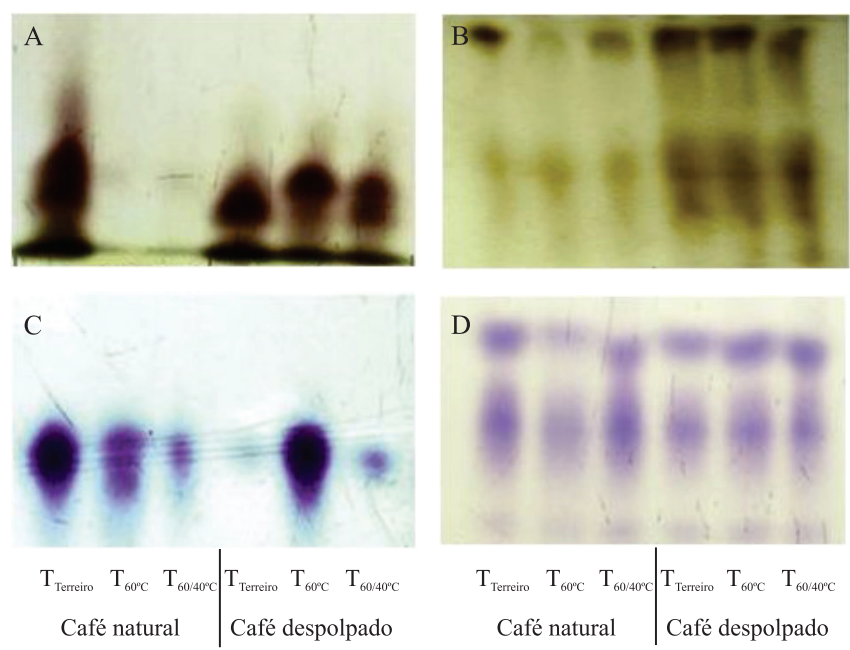

Figura 3. Perfil eletroforético das isoenzimas: A, esterase; $\mathrm{B}$, polifenoloxidase; C, isocitrato desidrogenase; e D, malato desidrogenase, em sementes de café submetidas aos processamentos via seca (café natural) e via úmida (café despolpado), secadas em terreiro $\left(\mathrm{T}_{\text {Terreiro }}\right)$ e em secador a 60 $\left(\mathrm{T}_{60^{\circ} \mathrm{C}}\right)$ e a $60 / 40^{\circ} \mathrm{C}\left(\mathrm{T}_{60 / 40^{\circ} \mathrm{C}}\right)$. no campo e de frutos sobremaduros. Muitos fatores podem influenciar a atividade da PPO; contudo, no presente trabalho, foi possível isolar e avaliar, adequadamente, o efeito dos diferentes tratamentos de secagem sobre os grãos, possivelmente pelo fato de estes terem sido colhidos de maneira uniforme, no estádio cereja de maturação.

A maior atividade da IDH foi observada em café natural, principalmente quando secado no terreiro (Figura $3 \mathrm{C}$ ). A secagem com ar aquecido a $60^{\circ} \mathrm{C}$ e a $60 / 40^{\circ} \mathrm{C}$ diminuiu sua atividade. Já no café despolpado, a maior atividade foi observada quando o café foi secado a $60^{\circ} \mathrm{C}$, e quase nenhuma atividade foi verificada quando secado a $60 / 40^{\circ} \mathrm{C}$ ou no terreiro. Mudanças nas rotas de respiração dos grãos podem ocorrer durante o processamento e a secagem, já que estes são submetidos a diferentes temperaturas - o que afeta as taxas de respiração - e pode haver baixa disponibilidade de oxigênio em algumas condições de processamento e secagem. A mudança nas rotas respiratórias pode determinar diferentes atividades da IDH, pois essa enzima está relacionada à respiração aeróbica e tem importante função no ciclo de Krebs (Taiz \& Zeiger, 2004). Há necessidade, no entanto, de estudos mais aprofundados para a determinação do momento em que essas mudanças ocorreriam durante o processamento e a secagem.

A atividade da enzima MDH foi semelhante em todos os tratamentos de secagem, tanto para os cafés naturais quanto para os cafés despolpados (Figura 3 D). Assim como a IDH, a MDH é uma enzima da rota respiratória e tem importante função de catálise da reação de malato a oxalato, na última reação do ciclo de Krebs (Santos et al., 2004; Taiz \& Zeiger, 2004; Coutinho et al., 2007). Brandão Júnior et al. (1999) observaram que a atividade da MDH foi a menos afetada pelos tratamentos de envelhecimento em sementes de milho. Há indícios de que essa maior estabilidade da enzima também tenha ocorrido durante o processamento e a secagem dos grãos de café, no presente trabalho.

Atualmente, é comum a aplicação de altas temperaturas em cafés naturais, para uma secagem rápida, e de temperaturas mais baixas nos despolpados. Esse procedimento é adotado por acreditar-se que, por ainda estarem nos frutos, as sementes de café natural seriam mais resistentes à secagem e estariam menos expostas do que os despolpados. Porém, com base nos resultados obtidos no presente trabalho, pode-se afirmar que os cafés processados por via úmida (despolpados) 
apresentam maior tolerância à secagem do que os processados por via seca (naturais). Assim, os dados obtidos podem fundamentar a indicação de mudança nos métodos de secagem comumente adotados em fazendas cafeeiras e, também, ser precursores de estudos e inovações no desenvolvimento de metodologias de secagem mais rápidas ou com temperaturas mais baixas.

Para tanto, são necessárias mais pesquisas para detectar o momento em que as transformações nos perfis proteicos ocorrem, o que contribuiria para aprimorar as tecnologias pós-colheita para a obtenção de cafés de melhor qualidade.

\section{Conclusões}

1. O perfil proteico em grãos é afetado pelo método de processamento e de secagem.

2. O café processado via úmida apresenta maior tolerância à secagem do que o processado por via seca, revelada pela maior atividade de enzimas antioxidantes e pelo melhor desempenho fisiológico.

3. A atividade das proteínas resistentes ao calor e das enzimas antioxidantes é variável promissora para diferenciar a qualidade dos cafés submetidos a diferentes manejos pós-colheita.

\section{Agradecimentos}

À Fundação deAmparoà Pesquisa do Estado de Minas Gerais, ao Conselho Nacional de Desenvolvimento Científico e Tecnológico e à Coordenação de Aperfeiçoamento de Pessoal de Nível Superior, pelo apoio financeiro.

\section{Referências}

ALFENAS, A.C. Eletroforese e marcadores bioquímicos em plantas e microrganismos. 2.ed. Viçosa: UFV, 2006. 627p.

AMORIM, H.V. Aspectos bioquímicos e histoquímicos do grão de café verde relacionados com deterioração da qualidade. 1978. 85p. Tese (Doutorado) - Escola Superior de Agricultura Luiz de Queiroz, Piracicaba.

BAILlY, C.; BENAMAR, A.; CORBINEAU, F.; CÔME, D. Changes in malondialdehyde content and in superoxide dismutase, catalase and glutathione reductase activities in sunflower seeds as related to deterioration during accelerated aging. Physiologia Plantarum, v.97, p.104-110, 1996.

BERJAK, P. Unifying perspectives of some mechanisms basic to desiccation tolerance across life forms. Seed Science Research, v.16, p.1-15, 2006.
BORÉM, F.M. Processamento do café. Lavras: UFLA, 2008. $631 \mathrm{p}$.

BORÉM, F.M.; CORADI, P.C.; SAATH, R.; OLIVEIRA, J.A. Qualidade do café natural e despolpado após secagem em terreiro e com altas temperaturas. Ciência e Agrotecnologia, v.32, p.1609-1615, 2008.

BRANDÃO JÚNIOR, D.S.; CARVALHO, M.L.M. de; VIEIRA, M. das G.G.C. Variações eletroforéticas de proteínas e isoenzimas relativas à deterioração de sementes de milho envelhecidas artificialmente. Revista Brasileira de Sementes, v.21, p.114-121, 1999.

BRANDÃO JÚNIOR, D.S.; VIEIRA, M. das G.G.C.; HILHOST, H.W.M. Aquisição da tolerância à dessecação nos diferentes estádios de desenvolvimento de sementes de cafeeiro (Coffea arabica L.). Ciência e Agrotecnologia, v.26, p.673-681, 2002.

BYTOF, G.; KNOPP, S.-E.; KRAMER, D.; BREITENSTEIN, B.; BERGERVOET, J.H.W.; GROOT, P.C.; SELMAR, D. Transient occurrence of seed germination processes during coffee post-harvest treatment. Annals of Botany, v.100, p.61-66, 2007.

COUTINHO, W.M.; SILVA-MANN, R.; VIEIRA, M. das G.G.C.; MACHADO, C.F.; MACHADO, J.C. Qualidade sanitária e fisiológica de sementes de milho submetidas à termoterapia e condicionamento fisiológico. Fitopatologia Brasileira, v.32, p.458-464, 2007.

DUSSERT, S.; DAVEY, M.W.; LAFFARGUE, A.; DOULBEAU, S.; SWENNEN, R.; ETIENNE, H. Oxidative stress, phospholipids loss and lipid hydrolysis during drying and storage of termediate seeds. Physiologia Plantarum, v.127, p.192-204, 2006.

FARIA, M.A.V.F.; VON PINHO, R.G.; VON PINHO, E.V. de R.; GUIMARÃES, R.M. Marcadores moleculares da qualidade fisiológica de sementes. Lavras: UFLA/FAEPE, 2003. 51p.

FORTES, M.; FERREIRA, A.D.; FERREIRA, W.R.; SOUZA, A.C. de. Modelagem de um condicionador de ar de alta precisão para uso em processamento agrícola. Engenharia Agrícola, v.26, p.578-589, 2006

GOULART, P.F.P. Análise comparativa entre lixiviação de potássio, condutividade elétrica, teor de ácido clorogênico e métodos de quantificação da atividade da polifenoloxidase em extratos semipurificados de amostras de café de diferentes padrões de qualidade. Revista Brasileira de Armazenamento, n.7, p.78-85, 2003.

GREGGAINS, V.; FINCH-SAVAGE, W.E.; QUICK, W.P.; ATHERTON, N.M. Metabolism-induced free radical activity does not contribute significantly to loss of viability in moist-stored recalcitrant seeds of contrasting species. New Phytologist, v.148, p.267-276, 2000.

GUIMARÃES, R.M.; VIEIRA, M. das G.G.C.; FRAGA, A.C.; PINHO, É.V. de R. von; FERRAZ, V.P. Tolerância à dessecação em sementes de cafeeiro (Coffea arabica, L). Ciência e Agrotecnologia, v.26, p.128-139, 2002.

LI, C.; SUN, W. Desiccation sensitivity and activities of free radical-scavenging enzymes in recalcitrant Theobroma cacao seeds. Seed Science Research, v.9, p.209-217, 1999. 
LIVRAMENTO, K.G. Proteômica diferencial de café arábica submetido a diferentes processamentos e secagem. 2008. 67p. Dissertação (Mestrado) - Universidade Federal de Lavras, Lavras.

MARQUES, E.R.; BORÉM, F.M.; PEREIRA, R.G.F.A.; BIAGGIONI, M.A.M. Eficácia do teste de acidez graxa na avaliação da qualidade do café arábica (Coffea arabica L.) submetido a diferente períodos e temperaturas de secagem. Ciência e Agrotecnologia, v.32, p.1557-1562, 2008.

NKANG, A.; OMOKARO, D.; EGBE, A. Effects of desiccation on the lipid peroxidation and activities of peroxidase and polyphenoloxidase in seeds of Telfairia occidentalis. Seed Science and Technology, v.28, p.1-9, 2000.

PIMENTA, C.J.; VILELA, E.R. Efeito do tipo e época de colheita na qualidade do café (Coffea arabica L.). Acta Scientiarum: Agronomy, v.25, p.131-136, 2003.

SANTOS, C.M.R.; MENEZES, N.L. de; VILLELA, F.A. Alterações fisiológicas e bioquímicas em sementes de feijão envelhecidas artificialmente. Revista Brasileira de Sementes, v.26, p.110-119, 2004.

SANTOS, M.A.; CHALFOUN, S.M.; PIMENTA, C.J. Influência do processamento por via úmida e tipos de secagem sobre a composição, físico química e química do café (Coffea arabica L.). Ciência e Agrotecnologia, v.33, p.213-218, 2009.

REGRAS para análise de sementes. Brasília: Ministério da Agricultura e Reforma Agrária, Secretaria Nacional de Defesa Agropecuária 2009. 399p.

TAIZ, L.; ZEIGER, E. Fisiologia vegetal. 3.ed. Porto Alegre: Artmed, 2004. 719p.

TAWFIK, M.S.; HUYGHEBAERT, A. Interaction of packaging materials and vegetable oils: oil stability. Food Chemistry, v.64, p.451-459, 1999.

VIDIGAL, D.S.; DIAS, D.C.F.S.; VON PINHO, E.R.; DIAS, L.A.S. Sweet pepper seed quality and Lea-protein activity in relation to fruit and post-harvest storage. Seed Science and Technology, v.31, p.192-201, 2009.

Recebido em 7 de janeiro de 2012 e aprovado em 28 de setembro de 2012 